Elektrik Elektronik Mühendisliği / Elecrical Electronic Engineering

\section{Araştırma Makalesi / Research Article}

Geliş tarihi / Received:12.10.2021
ISSN: 2146-0574, eISSN: 2536-4618 DOI: 10.21597/jist.1008632

Atıf İçin: Gürkan S, Aytav E, 2022. Fotovoltaik Panel Emülatörü Tasarımında Dijital İkiz Kullanımı. Iğdır Üniversitesi Fen Bilimleri Enstitüsü Dergisi, 12(1): 194-206.

To Cite: Gürkan S, Aytav E, 2022. Using Digital Twin in Photovoltaic Panel Emulator Design. Journal of the Institute of Science and Technology, 12(1): 194-206.

\title{
Fotovoltaik Panel Emülatörü Tasarımında Dijital İkiz Kullanımı
}

\section{Serkan GÜRKAN ${ }^{1 *}$, Emre AYTAV ${ }^{2}$}

ÖZET: Fotovoltaik paneller ile gerçekleştirilen uygulamalı eğitimlerde karşılaşılan problemlerden birisi de uygulanacak 1şığın kaynağıdır. Güneşin günün her vaktinde istenen şiddette olmaması ve meteorolojik olaylar nedeniyle dış ortamda doğal 1şık kullanarak eğitim yapmak oldukça zordur. Kapalı ortamlardaki uygulamalı eğitimlerde ise panele doğal güneş 1 şığı uygulamak yerine büyük hacimli ve güç gereksinimi fazla olan yapay 1şık kaynakları kullanmak en sık tercih edilen yöntemdir. Fotovoltaik paneller ile aynı elektriksel özelliklere sahip bir emülatör ile doğal veya yapay ışık kaynağına ihtiyaç duymadan düşük maliyetler ile uygulamalı eğitimler gerçekleştirilebilir. Bu çalışmada, önemli bir yenilenebilir enerji kaynağı olan fotovoltaik hücrenin tek diyotlu modeli esas alınarak bir fotovoltaik panel emülatörü tasarlanmış; düşük maliyetli, deneysel çalışmalar için ışık kaynağına ihtiyaç duymayan, öğrencilerde psikomotor ve bilişsel davranışların geliştirilebileceği prototip bir sistem ortaya çıkarılmıştır. Emülatörün tasarımı için ticari maksatlı üretilen bir fotovoltaik panel referans alınmış ve elektriksel özellikleri tespit edilmiştir. Tasarlanan emülatörün doğrulanmasında kullanılmak üzere referans panel için dijital ikiz oluşturulmuştur. Geliştirilen emülatörde; güneşlenme miktarı $50 \mathrm{~W} \mathrm{~m}^{-2}$ ile $1000 \mathrm{~W} \mathrm{~m}^{-2}$ aralığında, panel sıcaklığ $10^{\circ} \mathrm{C}$ ile $80^{\circ} \mathrm{C}$ aralığında bilgisayar aracılığı ile değiştirilebilir. Emülatörde $10 \mathrm{~W}$ maksimum güç hedeflenmiş, $\% 0.1$ hata ile $10.01 \mathrm{~W}$ maksimum güç elde edilmiştir. Geliştirilen emülatörün dijital ikizi ile yapılan doğrulamasında elde edilen elektriksel verilerin, referans panelin elektriksel verileri ile uyumlu olduğu görülmüştür.

Anahtar Kelimeler: Dijital ikiz, FV panel, FV panel emülatörü, enerji teknolojileri, yenilenebilir enerji

\section{Using Digital Twin in Photovoltaic Panel Emulator Design}

ABSTRACT: One of the problems encountered in training with photovoltaic panels is the source of light to be applied. It is difficult to train with natural light due to the fact that the sun is not at the desired intensity at all times of the day and meteorological events. In training in indoor environments, instead of applying natural sunlight to the panel, using artificial light sources with large volumes and high power requirements is the most preferred method. With an emulator with the same electrical characteristics as photovoltaic panels, practical training can be carried out at low costs without the need for natural or artificial light sources. In this study, a photovoltaic panel emulator was designed based on the single diode model of the photovoltaic cell, and a prototype system has been revealed that does not need a light source in experimental studies and can improve psychomotor behaviors on students. The electrical properties of a commercially produced photovoltaic panel were taken as reference for the design of the emulator. A digital twin has been created for the reference panel to be used in the verification of the designed emulator. In the developed emulator; the amount of sun exposure and the panel temperature can be changed by computer. In the emulator, $10 \mathrm{~W}$ maximum power was targeted, and $10.01 \mathrm{~W}$ has been obtained with an error of $0.1 \%$. In the verification of the developed emulator with its digital twin, it has been seen that the electrical data obtained were compatible with the electrical data of the reference panel.

Keywords: Digital twin, PV panel, PV panel emulator, energy technologies, renewable energy

${ }^{1}$ Serkan GÜRKAN (Orcid ID: 0000-0003-2229-3361), Milli Savunma Üniversitesi, Kara Astsubay MYO, Elektronik Haberleşme Teknolojisi Bölümü, Balıkesir, Türkiye

${ }^{2}$ Emre AYTAV (Orcid ID: 0000-0003-4296-6703), Milli Savunma Üniversitesi, Kara Harp Okulu, Makine Mühendisliği Bölümü, Ankara, Türkiye

*Sorumlu Yazar/Corresponding Author: Serkan GÜRKAN, e-mail: sgurkan@msu.edu.tr 


\section{GİRiş}

Giderek artan dünya nüfusu, sanayi alanındaki gelişmeler ve teknolojik aygıtların kullanımının her geçen gün artması enerjiye olan gereksinimi de artırmaktadır. Enerji, kişisel maksatlı kullanımdan sanayi kullanımına kadar geniş bir yelpazede en temel girdi olarak karşımıza çıkmaktadır. Tüm bu gelişmeler dünyada enerji tüketiminin yılda ortalama \%4-5 artmasına sebep olmaktadır (Aydın, 2014; Kaya ve ark., 2018). Günümüzde enerji elde etmek için kullanılan kaynaklar arasında yenilenebilir enerji, nükleer enerji, kömür, doğalgaz, petrol ve hidroelektrik enerji sayılabilir. 2019 yılında, dünyadaki enerji tüketiminin kaynaklar bazındaki dağılımı; \%33.1 petrol, \%24.2 doğalgaz, \%27 kömür, \%5 yenilenebilir enerji, \%6.4 hidroelektrik, \%4.3 nükleer enerji şeklinde gerçekleşmiştir (Anonim, 2020). Bu değerlere göre 2019 yılında dünyada tüketilen enerjinin \%84.3’ü fosil yakıtlardan elde edilmiştir. Dünyada yenilenebilir enerji kaynaklarından üretilen enerji miktarları incelendiğinde, 2009 yılında 636.7 terawatt saat $^{-1}$ olan üretimin 2019 y1lında 2805.5 terawatt saat ${ }^{-1}$ olarak gerçekleştiği ve 4.4 kat arttığ görülmektedir (Anonim, 2020). Dünyadaki yenilenebilir enerji kaynaklarının çeşitliliğini, verimliliğini ve miktarını arttırmaya yönelik ulusal ve uluslararası birçok çalışma yapılmaktadır.

Fosil enerji rezervlerinin yetersizliği, enerjiye olan yüksek gereksinim ve barındırdığı yüksek potansiyel nedeniyle yenilenebilir enerji Türkiye için önemli bir enerji kaynağıdır (Gençer ve ark., 2009; Bayramoğlu, 2018; Kaya ve ark., 2018; Yılmaz ve Öziç, 2018; Kavcığlu, 2019;).

Hidro, güneş, rüzgâr, jeotermal, biyokütle ve hidrojen enerjileri günümüzde en sık kullanılan yenilenebilir enerji kaynaklarıdır. Bunların içerisinde güneşten elde edilen enerji birçok sektörde kullanım alanı bulmaktadır. Elde edilmesi, depolanması ve işletilmesi noktasında sağladığı avantajlar nedeniyle sık tercih edilen yenilenebilir enerji kaynaklarındandır. Güneşten aldığı enerjiyi elektrik enerjisine çeviren kaynakların en küçük yapısına fotovoltaik (FV) hücre denir. FV hücreler güneş tarafından yayınlanan termal radyasyona maruz kaldığında termal enerji soğurulur ve DC elektrik enerjisi elde edilir. FV hücrelerin boyutu küçük, verebileceği DC gerilim ve enerjisi düşüktür. Bu hücrelerin seri ve paralel bağlanmasıyla bir dizi meydana getirilerek FV panel elde edilir (Tagare, 2011). Elde edilen enerjinin doğrudan depolanabilmesi ve kullanılabilmesi FV panellerin en önemli avantajlarındandir.

Yenilenebilir enerji kaynaklarından elde edilen enerjinin üretilen toplam enerji miktarındaki payının artırılmasında ve bu enerji kaynaklarına geçiş aşamasında; sistemlerin tasarlanması, enerjinin dağıtımı, işletme ve bakım-onarım faaliyetlerinin idamesi için nitelikli personele ihtiyaç duyulmaktadır (Alqahtani ve ark., 2018). Nitelikli teknik personel yetiştirilmesi için yenilenebilir enerji alanında eğitim veren kurumlardaki ders müfredatlarının düzenlenmesi ve yeni eğitim-öğretim materyallerinin geliştirilmesi önem kazanmaktadır (Kacan, 2015).

Literatür araştırıldığında FV panellerin öğretimine yönelik yapılan şu çalışmalar ile karşılaşılmıştır. Bilgisayar ortamında ticari bir FV panelin FV hücre modeli ile modellendiği çalışmada, elde edilen modelin FV sistem tasarımlarında ve genel sistem simülasyonu çalışmalarında kullanılabileceği belirtilmiştir (İşen ve Koçhan, 2020). Yenilenebilir enerji mühendisliği eğitimine yönelik gerçekleştirilen bir diğer çalışmada güneşlenme ve açık devre gerilim değerleri kademeli ayarlanabilen bilgisayar destekli bir FV emülatör sistemi geliştirilmiştir (Gürkan ve ark., 2020). İki farklı firmanın FV panellere yönelik eğitimlerde kullanılmak üzere ticari maksatlı geliştirdikleri deney donanımlarında 2 adet FV panel kullanılmış, deneysel çalışmalarda ihtiyaç duyulan ışık halojen lambalar vasıtasıyla sağlanmıştır (Anonim, 2019; Anonim, 2021).

Özellikle ticari maksatlı üretilen FV panel eğitim donanımlarında deneysel çalışma gerçekleştirmek için ya doğrudan güneş ışığına ya da yapay ışık kaynaklarına ihtiyaç duyulmaktadır. 
Doğrudan güneş 1şı̆̆ı ile yapılan deneysel çalışmalarda zamana ve mevsimsel değişiklere bağlı olarak kısıtlamalar söz konusu olmakta, eğitimler neticesinde oluşturulmak istenen davranışların kısmen kazandırılamaması gibi problemler yaşanabilmektedir. Yapay 1şık kaynakları ile gerçekleştirilen deneysel çalışmalarda ise ihtiyaç duyulan güneşlenme miktarını elde edebilmek için yüksek güçlü aydınlatma dizilerine ihtiyaç duyulmaktadır.

Bu çalışmada; güneş ışığı veya harici ışık kaynağına ihtiyaç duymadan, deneysel çalışmalarda FV panelin yerine kullanılabilecek bir FV panel emülatörün tasarımı gerçekleştirilmiştir. Çalışma kapsamında TERA Solar TRP-010B (Anonim, 2018) FV panelin dijital ikizi oluşturularak bu panel ile benzer elektriksel özelliklere sahip bir FV emülatör tasarımı gerçekleştirilmiştir. FV emülatörün elektriksel özelliklerini doğrulamak ve değerlendirmek için dijital ikiz yöntemi kullanılmıştır. Geliştirilen FV emülatörde, güneşlenme miktarı ve sıcaklık değerleri sürekli ayarlanabilmektedir. Güneşlenme parametresi $50 \mathrm{~W} \mathrm{~m}^{-2}$ ile $1000 \mathrm{~W} \mathrm{~m}^{-2}(\% 5-\% 100)$, sicaklık parametresi ise $0{ }^{\circ} \mathrm{C}$ ile $80{ }^{\circ} \mathrm{C}$ aralığında değiştirilebilmektedir.

\section{MATERYAL VE METOT}

\section{FV Hücrenin Tek Diyot Modeli}

FV hücrelerin elektriksel karakteristiğinin belirlenmesinde ve davranışlarının incelenmesinde yararlanılan tek diyot ve çift diyot modelleri bulunmasına karşın, tek diyot modeli en yaygın kullanılanıdır (Can, 2013). Bir FV hücrenin tek diyot modeline ait eşdeğer devre Şekil 1'de, devrenin çıkış akımını hesaplamada kullanılan eşitlik ise Eşitlik 1'de verilmiştir. Eşitlik 1'de; I: FV hücre çııış akımı (A), $I_{p h}$ : ş̧ık kaynaklı akım (A), $I_{o}$ : diyot ileri yön doyum akımı (A), $V$ : FV hücre çıkış gerilimi $(\mathrm{V}), R_{s h}$ : paralel kaçak akım direnci $(\Omega), R_{s}$ : Hücre iç direnci ile bağlantı dirençleri $(\Omega), V_{t}$ : termal gerilimdir (V). $V_{t}$ ise Eşitlik 2'deki gibi hesaplanabilir. Eşitlik 2'de; $N_{s}$ : hücre sayısı, $n$ : diyot ideallik faktörü, $k_{b}$ : Boltzman sabiti $\left(1.38 \times 10^{-23} \mathrm{j} \mathrm{K}^{-1}\right), T$ : çalışma sıcaklığı $(\mathrm{K}), q$ : bir elektron yüküdür $(-1.6 \times$ $\left.10^{-19}\right)$.

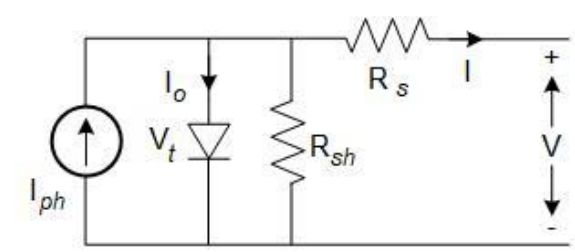

Şekil 1. FV hücrenin tek diyot modeli eşdeğer devresi

$$
\begin{aligned}
& I=I_{p h}-I_{o} \cdot\left(e^{\frac{V+R_{s} \cdot I}{V t}}-1\right)-\frac{V+R_{s} \cdot I}{R_{s h}} \\
& V_{t}=\frac{N_{s} \cdot n \cdot k_{b} \cdot T}{q}
\end{aligned}
$$

\section{Dijital İkiz}

Dijital ikiz kavramı NASA'nın Apollo programına dayanmaktadır (Rosen ve ark., 2015). Apollo programı kapsamında özdeş iki uzay aracı geliştirilmiş, görevler esnasında uzay koşullarını oluşturabilmek için yeryüzünde bırakılan araca "Dijital İkiz" denmiştir (Shangguan ve ark., 2020). İkiz araç genellikle görev öncesi hazırlıklar için eğitim maksadıyla kullanılmıştır. İkiz aracın temel görevi, uzay aracının durumunu yansıtmak ve tahmin etmek, böylece acil durumlarda uzay yörüngesindeki astronotlara en doğru kararları vermeleri için yardımcı olmaktır. 2002 yılında Dr. Micheal Grieves tarafından ilk defa kullanılan dijital ikiz kavramının 2006 yılında kavramsal temelleri atılmıştır (Grieves, 2006, 2016; Kumaş ve Erol, 2021). Veri toplama, sinyal işleme, modelleme, benzetim ve diğer dijital teknolojilerin gelişmesiyle dijital ikiz kavramı daha somut bir hale gelmiştir. Dijital ikiz; ayrılabilir, yeniden üretilebilir, aktarılabilir, değiştirilebilir, silinebilir ve tekrarlanabilir bir dijital kopya oluşturmak 
için fiziksel varlıkların çeşitli niteliklerini dijital dünyaya eşler (Boschert ve Rosen, 2016; Tao ve ark., 2017). Dijital ikiz gerçek verileri ve model verilerini sentezlemekle kalmaz, aynı zamanda fiziksel varlıkları farklı boyutlardan inceleme firsatı sunar. Dijital ikiz kavramı, Nesnelerin İnterneti (IoT) sayesinde farklı sektörlerde düşük maliyetlerle kullanılabilir hale gelmiştir ve akıllı şehir, hava araçları, enerji yönetimi, inşaat, üretim, sağlık, mühendislik, madencilik, arızacılık gibi birçok farklı sektörde kullanım alanı bulmuştur (Fuller ve ark., 2020). Savunma, sağlık, otomotiv, havacılık, enerji gibi imalat ve test aşaması maliyetleri yüksek olan sektörlerde fiziki ortamdan alınan veriler ile dijital ikiz oluşturulması, verilerin izlenmesi, üretim hatalarının öngörülmesi ve gerekli tedbirlerin alınması maliyet etkin ve güvenilir çıktıların elde edilmesini sağlar. Son yıllarda yenilenebilir enerji sistemleri ve akıllı şebekeler dijital ikiz teknolojisinin etkin şekilde kullanıldığı sektörlerdir (Khaled ve ark., 2020; Bartie ve ark., 2021; Guarino ve ark., 2021). Dijital ikizin çalışmasını gösteren bir mikro akıllı şebekenin blok diyagramı Şekil 2'de gösterilmektedir.

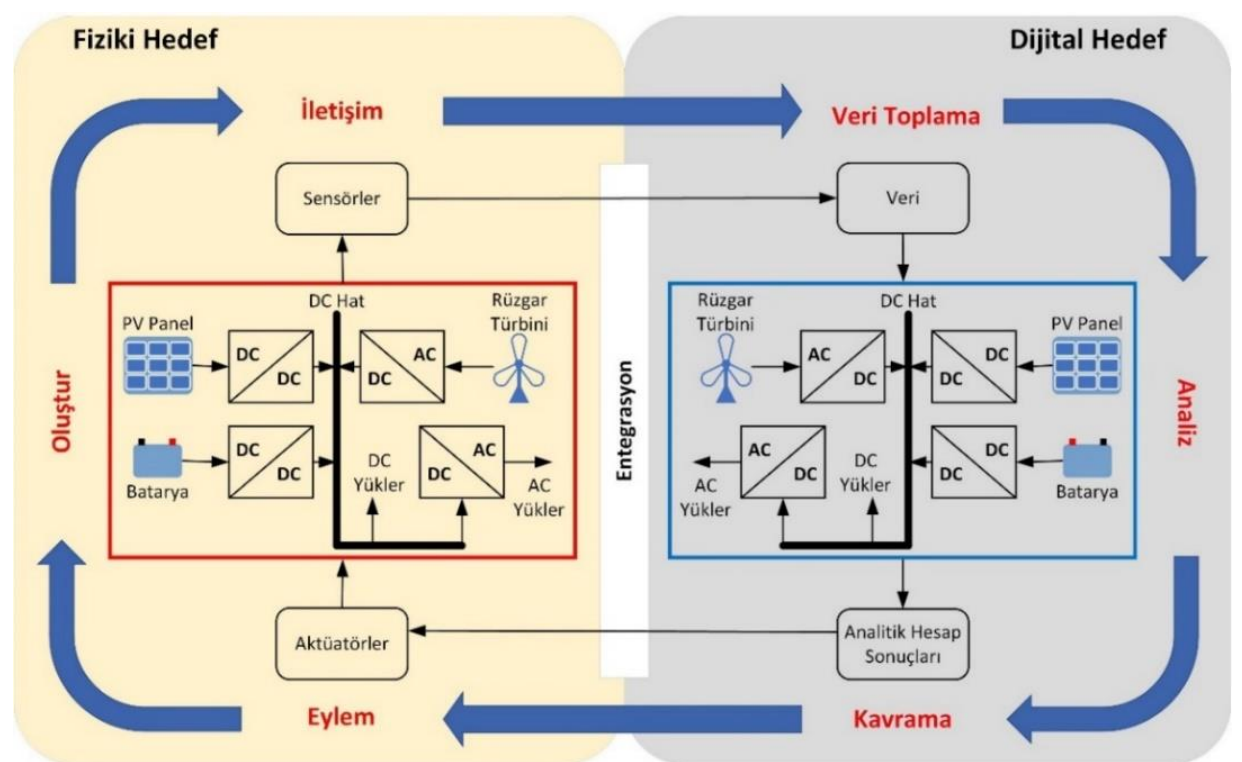

Şekil 2. Dijital ikiz bileşenleri içeren bir mikro akıllı şebekeye ait blok şema

Dijital ikizde fiziki ve dijital hedefler için iki döngü vardır ve döngülerde sensörler ile aktüatörler bulunur. Sensörler, verileri fiziki hedeften toplar ve dijital hedefe aktarır. Dijital hedefte gerçekleştirilen işlemlerden elde edilen analitik sonuçlar, fiziki hedefin çalışmasını düzenlemek üzere aktüatörler aracılığıyla fiziki hedefe aktarılır. Dijital ikize ulaşmak için altı basamaktan oluşan bir işlemler dizisi takip edilir. Oluşturma safhasında; fiziki hedefe ait operasyonel (akım, gerilim, güç, frekans vb.) ve çevresel (sıcaklık, nem, güneşlenme, rüzgâr hızı vb.) ölçümler gerçekleştirilir. İletişim, fiziki hedef ile dijital hedef arasında iki yönlü haberleşmenin gerçekleştirildiği ve veri akışının sağlandığı safhadır. Veri toplama safhasında fiziki hedeften gelen veriler, dijital hedefte değerlendirilmek üzere bulut veya dahili bölgelere kaydedilir. Toplanan veriler, fiziki hedeften toplanan verileri analiz etmek ve görselleştirmek için kullanılır. Veri analistleri verileri analiz eder ve akıllı kararlar için fiziki hedefte iyileştirmeler yapar. Analiz edilen verilerin işlenmesiyle görselleştirme yapılabilir ve anomalilerin belirlenmesi için kullanıcı tarafından takip edilebilir. Fiziki hedefin daha fazla araştırılması, verilerin kavranmasıyla ve içselleştirilmesiyle mümkündür. Kavrama safhasında, fiziki hedef için gerçekleştirilecek akıllı eylemler tanımlanır. Dijital hedefte ele alınan veriler kontrol için aktüatörleri tetikler ve fiziki hedef kontrol edilir. Fiziki ve dijital hedefin kapalı döngü mimarisi, sistemin entegrasyonu ile gerçekleştirilir (Senthilnathan ve Annapoorani, 2019). 


\section{Sistem Tasarımı}

FV sistemlerin incelenmesi ve yenilenebilir enerji mühendisliği eğitimlerinde deneysel maksatlarla kullanılabilecek bir FV panel emülatör prototipi geliştirmek üzere gerçekleştirilen bu çalışmada tasarım aşamaları aşağıda ele alınmıştır. FV panel emülatör prototipinin geliştirilmesi üç temel safhada gerçekleştirilmiştir. Birinci safhada ticari maksatla üretilen bir FV panele ait elektriksel parametreler tespit edilmiş, ikinci safhada FV panelin dijital ikizi oluşturulmuş, üçüncü safhada FV panel ile benzer elektriksel özelliklere sahip FV panel emülatörü tasarlanarak prototipi imal edilmiştir.

\section{FV panelin elektriksel parametrelerinin tespit edilmesi}

Çalışma kapsamında TERA Solar TRP-010B FV panel referans alınmış, FV panelin temel elektriksel parametrelerinin tespit edilmesi için Şekil 3'te verilen deney düzeneği kurulmuştur.

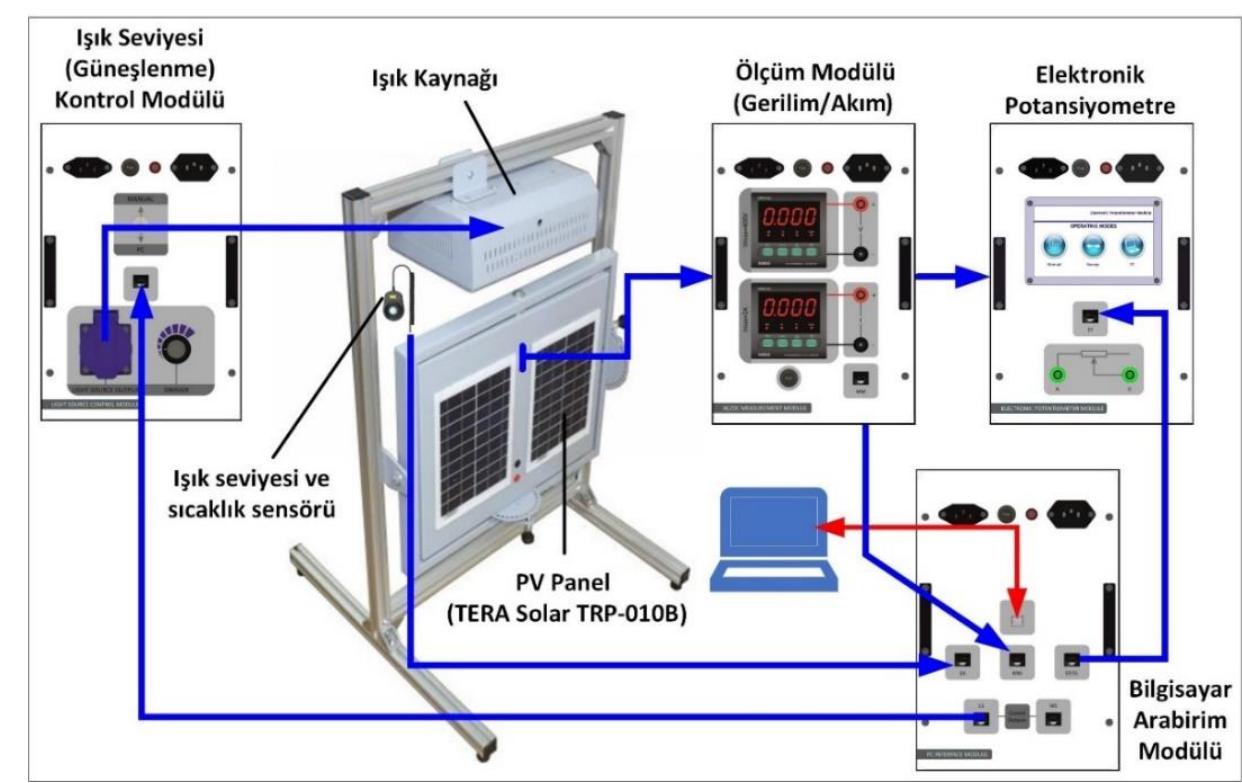

Şekil 3. FV panelin temel elektriksel parametrelerinin tespit edilmesi için kurulan deney düzeneği

Çalışmanın bundan sonraki bölümlerinde TERA Solar TRP-010B FV panelden 'Referans Panel' olarak bahsedilmiştir. Şekil 3 'te iki adet FV panel bulunmasına karşın bu panellerden yalnızca bir tanesi kullanılarak parametre tespiti gerçekleştirilmiştir. Deney düzeneği incelendiğinde, 1şık seviyesi kontrol modülü ile bir halojen lamba grubunun kontrol edilerek FV panelin güneşlenme miktarının ayarlanabildiği görülmektedir. Güneşlenme miktarının kontrolü bilgisayar arabirim modülü tarafından gerçekleştirilmektedir. Belirlenen güneşlenme miktarı altında FV panelin gösterdiği elektriksel tepkinin ölçülmesi için bir ölçüm modülü kullanılmıştır. Ölçüm modülü ile FV panelden çekilen akım ve gerilim değerleri ölçülerek bilgisayar arabirim modülüne aktarılır. Elektronik potansiyometre ile FV panelin yüklenme miktarı ayarlanmaktadır. Elektronik potansiyometre, bilgisayar arabirim modülü tarafından kontrol edilebilir ve FV panel çıkışı 0-10 K $\Omega$ aralığında omik değerlerle yüklenebilir. Diğer taraftan FV panel güneşlenme miktarı ve sıcaklığının ölçümü için kullanılan sensör, bilgisayar arabirim modülü ile iletişim halindedir.

\section{FV panel dijital ikizi}

Dijital ikizin önemli bir kullanım alanı da test edilmesi veya doğrulanması için fazla donanım gereken sistemlerin daha ekonomik şekilde test edilmesini ve doğrulanmasını sağlamaktır. FV paneller de gerçek ortamlarında rahatlıkla test edilemeyen ve test için fazla donanım gerektiren yenilenebilir enerji bileşenleridir. Diğer taraftan FV panel emülatörleri, FV panellerin donanımsal bir modelidir. Özellikle teknik eğitimde FV paneller ile gerçekleştirilecek deneysel çalışmalarda FV panel yerine kullanılarak zamandan ve maliyetten tasarruf edilebilir. Ticari maksatla üretilen bir FV panelden yola 
çıkarak oluşturulan dijital ikiz, FV panel ile yakın özelliklere sahip bir FV panel emülatörünün doğrulanması için kullanılabilir. Bu bilgiden hareketle, bu çalışmada elektriksel özellikleri belirlenen FV panel için bir dijital ikiz oluşturulmuş, sonraki bölümde tasarlanarak prototipi üretilen FV panel emülatörünün test edilmesi ve doğrulanması için kullanılmıştır. FV panel için tasarlanan dijital ikiz ve FV emülatörün doğrulanması için oluşturulan Simulink modeli Şekil 4’te verilmiştir.

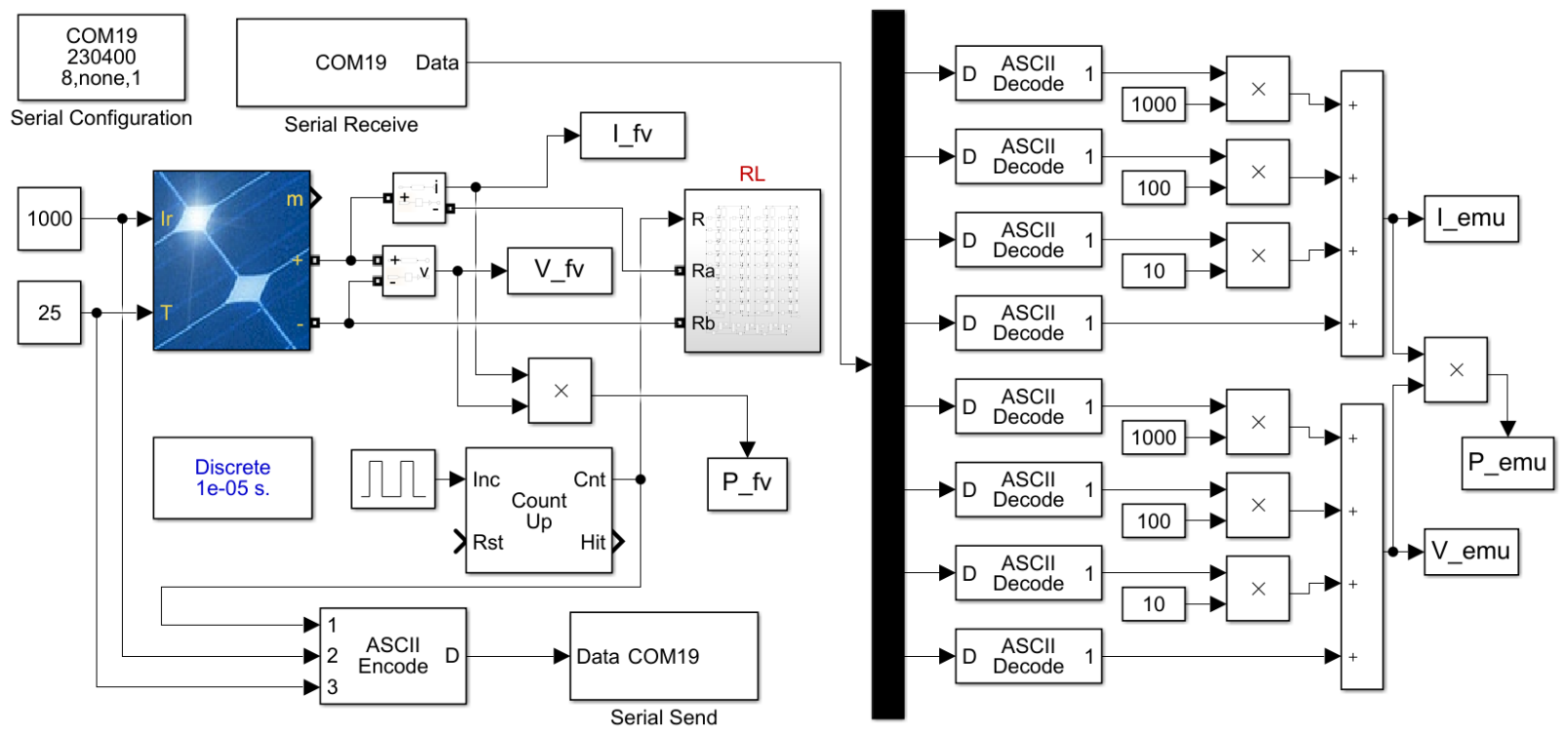

Şekil 4. FV panel için tasarlanan dijital ikiz ve FV emülatörün doğrulanması için oluşturulan Simulink modeli

\section{FV panel emülatörü}

Çalışma kapsamında; referans panelin temel elektriksel verileri referans alınarak, Şekil 1'de eşdeğer devresi verilen FV hücrenin tek diyot modeline dayalı bir FV panel emülatör tasarımı ve prototip üretimi gerçekleştirilmiştir. Tasarlanan FV panel emülatörünün devre şeması ve prototip emülatörün dış görünümü sırasıyla Şekil 5 ve Şekil 6'da verilmiştir. Mikrodenetleyici tabanlı üretilen FV panel emülatöründe güneşlenme, panel sicaklığı ve omik yük parametreleri bilgisayar destekli olarak ayarlanabilmektedir. Geliştirilen emülatör, bilgisayar ile kontrol edilebildiği gibi üzerinden manuel ayar yapılarak da işlemler gerçekleştirilebilmektedir. Emülatör ile bilgisayar arasındaki iletişim çalışma kapsamında geliştirilen bir protokolle yürütülmektedir. Bilgisayardan emülatöre doğru olan iletişimde; emülatör için gerekli olan güneşlenme, sıcaklık ve omik yük parametre değerleri bilgisayardan gönderilir ve bu değerlerin gereği olan işlemler emülatördeki mikrodenetleyici tarafından gerçekleştirilir. Emülatörden bilgisayara doğru olan iletişimde ise, emülatör çıkışından ölçülen akım ve gerilim verileri bilgisayara aktarılır. Emülatör üzerinde elektronik potansiyometre modülünün omik yük değerinin kontrol edilebilmesi için bir iletişim terminali bulunmaktadır.

Atmega328 mikrodenetleyici kullanılarak geliştirilen emülatörde, hedeflenen kısa devre akımı olan 0.56 A akım değerini sağlamak için bir akım kaynağı tasarlanmıştır. Şekil 5'te verilen devrede U1, U5, R1-R3 ve Q1 devre elemanları akım kaynağını oluşturmaktadır. U5 (MCP41HV51-104E), mikrodenetleyici tarafından kontrol edilen dijital bir potansiyometredir. Akım kaynağının sağlayabileceği maksimum akım 1 A'dir. R1, R2 ve U5 devre elemanları sayesinde akım kaynağının sağladığı akım 0.0275 A ile 0.57 A aralığında sürekli ayarlanabilir ve sınırlandırılabilir. Bu akım değerleri \%5 ile \%100 aralığına, diğer bir deyişle $50 \mathrm{~W} \mathrm{~m}^{-2}$ ile $1000 \mathrm{~W} \mathrm{~m}^{-2}$ aralığında güneşlenme miktarlarına karşılık gelmektedir. Güneşlenme referans değeri R7 ile ayarlanmaktadır. 0.57 A akım değeri emülatörden beklenen ISC değeridir. 


\section{Fotovoltaik Panel Emülatörü Tasarımında Dijital İkiz Kullanımı}

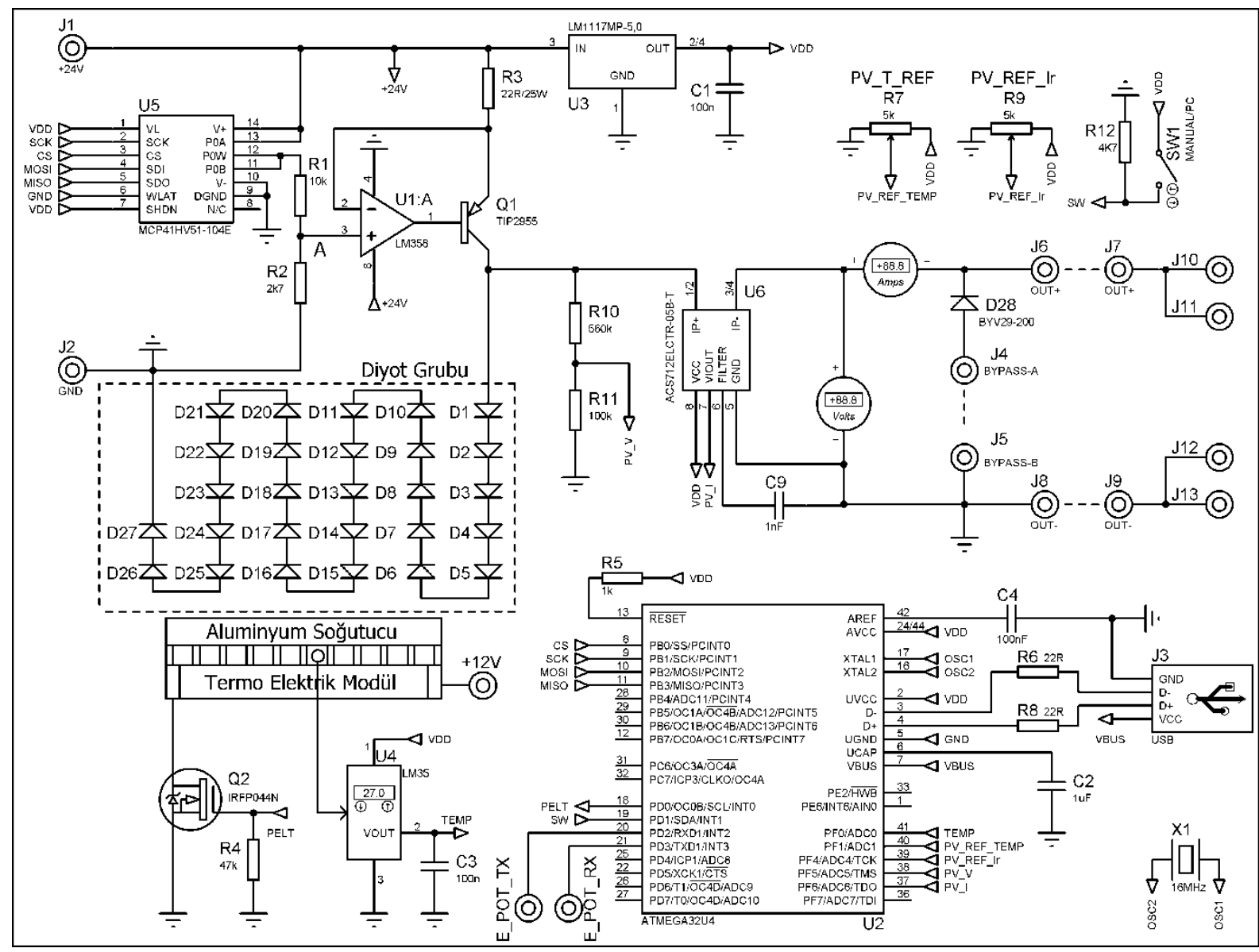

Şekil 5. Tasarlanan FV panel emülatörün devre şeması

Açık devre gerilimini belirleyen devre elemanları D1-D27'dir. Çalışmada ileri yön gerilimi (forward voltage) yaklaşık $0.85 \mathrm{~V}$ olan diyotlar tercih edilmiştir. Bu durumda diyot grubunda yer alan 27 adet diyodun eşdeğer ileri yön gerilimi teorik olarak 22.95 V olur. Bu değer geliştirilen emülatörden beklenen $\mathrm{V}_{\text {oc }}$ değeridir.

Yük altında veya yüksüz çalışmada diyot grubundan geçen akım 1sınmaya sebep olacaktır. Bu sıcaklık Eşitlik 2'deki $T$ parametresinin değişmesine ve dolayısıyla emülatörün diğer parametrelerinin değişmesine sebep olacaktır. Bu nedenle bilinen sabit şartlar altında incelemeler yapabilmek için $T$ değerinin kontrol altında tutulması gerekir. Bu maksatla diyot grubunun sıcaklık değerini sabit tutmak ve sabit sıcaklık altında FV panelin elektriksel davranışlarını incelemek için bir sıcaklık kontrol devresi tasarlanmıştır. Bunun için diyot grubu alüminyum soğutucuya ilişkilendirilmiş, alüminyum soğutucuya ise bir adet termo-elektrik modül (TEC1-12705) monte edilmiştir. Mikrodenetleyicide; U4 sıcaklık sensöründen elde edilen sıcaklık verisi ve R7 ile ayarlanan referans sıcaklık değeri karşılaştırılmakta, Q2 transistörü yardımıyla termo-elektrik modülün on-off kontrolü gerçekleştirilmektedir. Böylece diyot grubunun sıcaklığı $0^{\circ} \mathrm{C}$ ile $80{ }^{\circ} \mathrm{C}$ aralığında istenen değerde sabit tutulabilmektedir. 


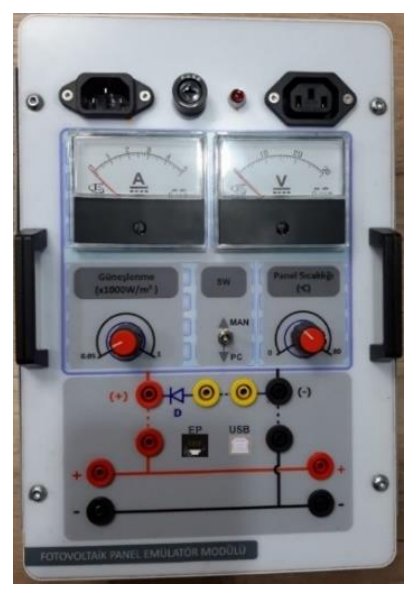

Şekil 6. Prototip FV panel emülatörün görünümü

\section{BULGULAR VE TARTIŞMA}

\section{Referans Panele Ait Elektriksel Parametreler}

Referans panele ait elektriksel parametrelerin elde edilmesi için Şekil 3'te verilen ölçme düzeneği kullanılmıştır. Kullanılan bu yapı sayesinde bilgisayar desteği ile FV panelin güneşlenme miktarı ayarlanmış, istenen yük koşullarında akım, gerilim, güneşlenme miktarı ve sıcaklık gibi parametreler elde edilebilmiştir. Referans panel için elde edilen temel elektriksel parametreler ve grafikler sırasıyla Çizelge 1 ve Şekil 7'de verilmiştir. Bu bölümde gerçekleştirilen çalışmalar $25{ }^{\circ} \mathrm{C}$ sicaklık altında gerçekleştirilmiştir. Çizelge 1 ve Şekil 7 incelendiğinde elde edilen sonuçların, referans panel (Anonim, 2018) elektriksel verileri ile uyumlu olduğu görülmektedir. Elde edilen sonuçlar, Şekil 3 'te verilen ölçüm düzeneğinin işlevini yerine getirdiğini ve referans panelin temel elektriksel verilerinin doğru şekilde elde edildiğini göstermektedir.

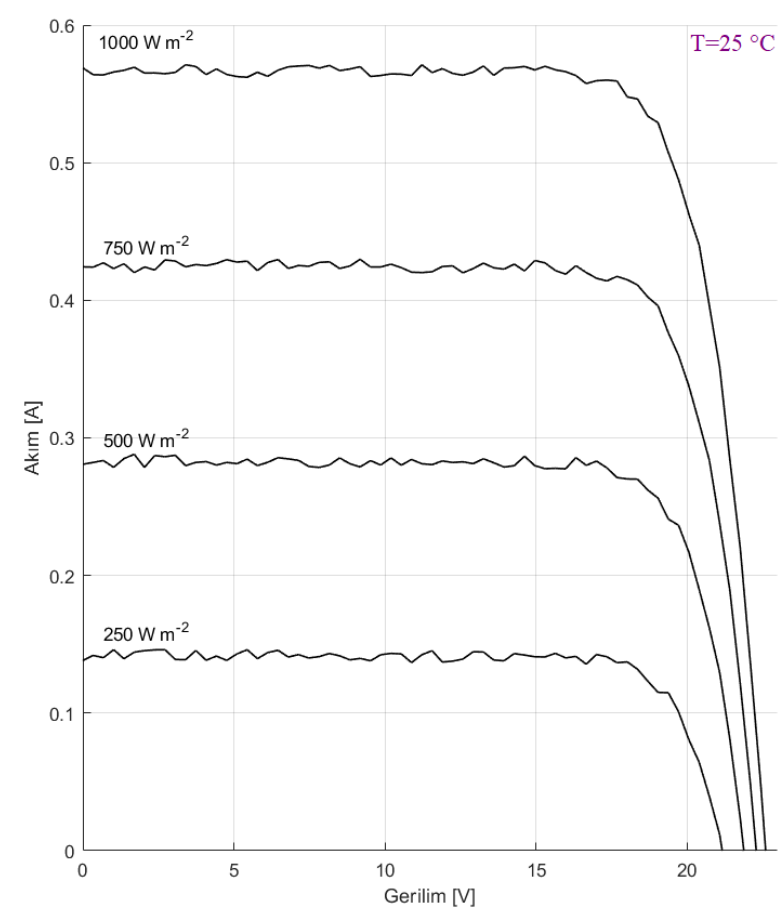

(a)

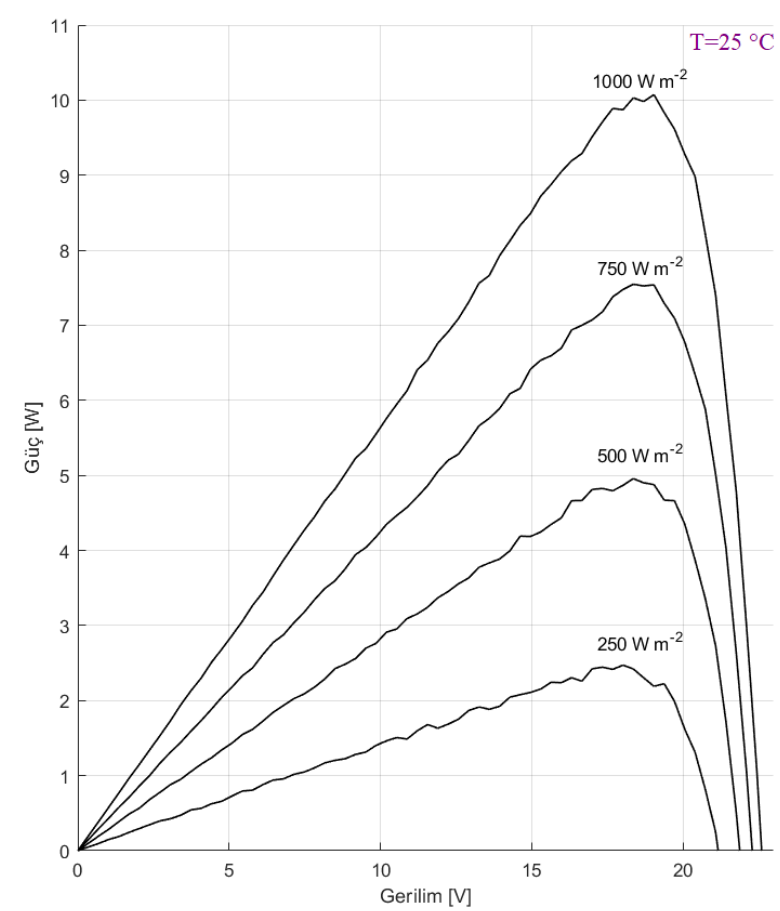

(b)

Şekil 7. Referans panel için elde edilen grafikler (a) I-V grafiği (b) P-V grafiği 
Çizelge 1. Referans panel için elde edilen temel elektriksel parametreler

\begin{tabular}{lccc}
\hline Parametre & $\begin{array}{c}\text { Katalog } \\
\text { Değeri }\end{array}$ & $\begin{array}{c}\text { Elde Edilen } \\
\text { Değer }\end{array}$ & Fark (\%) \\
\hline Maksimum Güç $\left(\mathrm{P}_{\max }\right)$ & $10.00 \mathrm{~W}$ & $10.03 \mathrm{~W}$ & +0.30 \\
Maksimum Güç Gerilimi $\left(\mathrm{V}_{\mathrm{mp}}\right)$ & $18.18 \mathrm{~V}$ & $18.70 \mathrm{~V}$ & +2.86 \\
Maksimum Güç Akımı $\left(\mathrm{I}_{\mathrm{mp}}\right)$ & $0.55 \mathrm{~A}$ & $0.54 \mathrm{~A}$ & -1.81 \\
Açık Devre Gerilimi $\left(\mathrm{V}_{\mathrm{OC}}\right)$ & $22.59 \mathrm{~V}$ & $22.61 \mathrm{~V}$ & +0.08 \\
Kisa Devre Akımı $\left(\mathrm{I}_{\mathrm{SC}}\right)$ & $0.57 \mathrm{~A}$ & $0.56 \mathrm{~A}$ & -1.75 \\
\hline
\end{tabular}

\section{Tasarlanan Dijital İkiz Performansının İncelenmesi}

Çalışma kapsamında tasarlanan dijital ikiz ile istenen güneşlenme, sıcaklık ve yük koşullarında grafiksel inceleme yapılabilir, dijital ikiz için kullanılan parametreler eşzamanlı olarak FV panel emülatörüne iletilebilir ve FV panel emülatörünün bu parametrelere tepkisi incelenebilir. Böylelikle FV panel emülatörü verileri ile FV panel verileri karşılaştırılmış olur. Şekil 4'te Simulink modeli verilen dijital ikiz için elde edilen grafikler Şekil 8'de, temel elektriksel parametreler ise Çizelge 2'de verilmiştir. Şekil 8 ve Çizelge 2 incelendiğinde; tasarlanan dijital ikizin, referans panelin temel elektriksel özelliklerini büyük ölçüde sağladığı görülmektedir. Elde edilen sonuçlar, literatürde PV paneller için geliştirilen diğer dijital ikiz modeli sonuçları ile (Khaled ve ark., 2020) uyumludur.

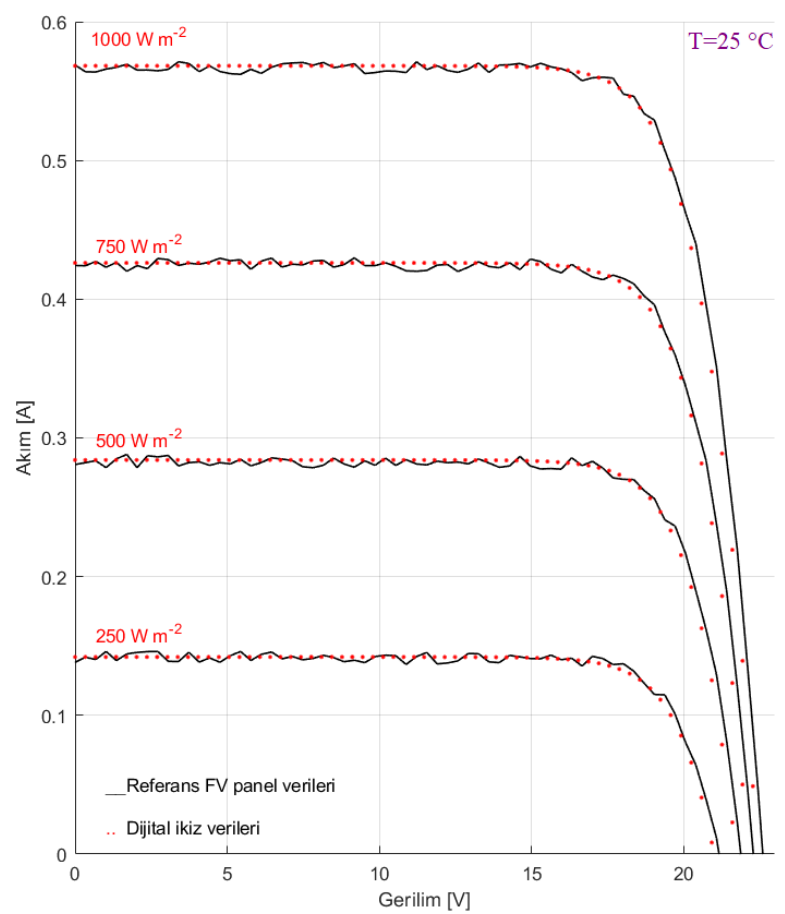

(a)

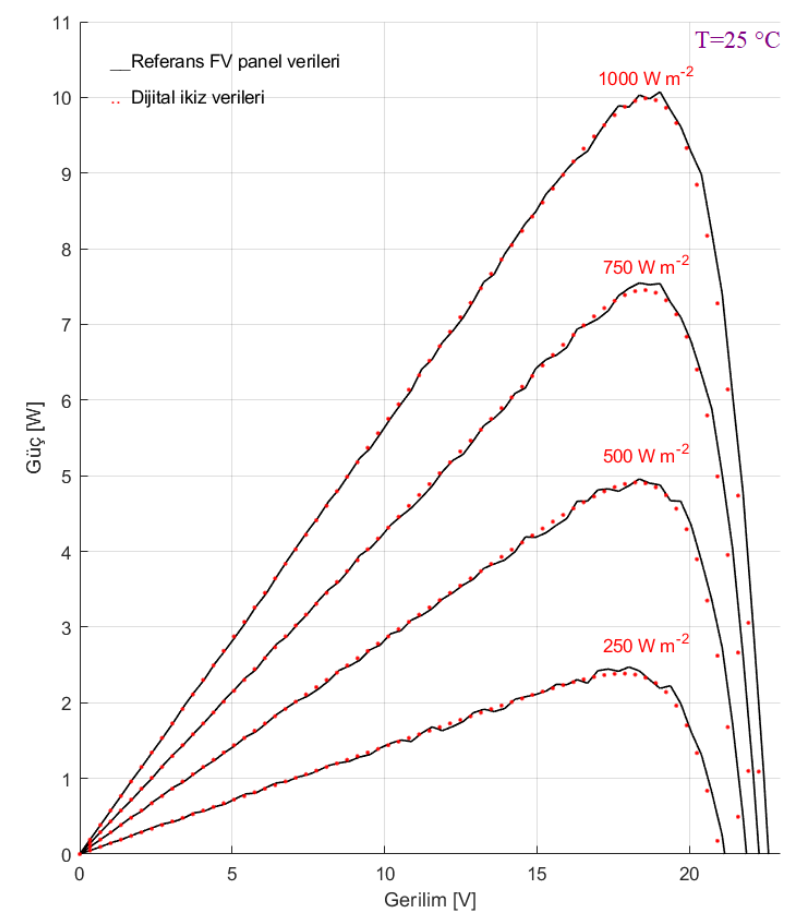

(b)

Şekil 8. FV panel dijital ikizi için elde edilen grafikler (a) I-V grafiği (b) P-V grafiği

Çizelge 2. FV panel dijital ikizi için elde edilen elektriksel parametreler

\begin{tabular}{lccc}
\hline Parametre & Referans FV Panel Değeri & Dijital İkiz Değeri & Fark (\%) \\
\hline Maksimum Güç $\left(\mathrm{P}_{\max }\right)$ & $10.03 \mathrm{~W}$ & $9.98 \mathrm{~W}$ & -0.50 \\
Maksimum Güç Gerilimi $\left(\mathrm{V}_{\mathrm{mp}}\right)$ & $18.70 \mathrm{~V}$ & $18.56 \mathrm{~V}$ & -0.75 \\
Maksimum Güç Akımı $\left(\mathrm{I}_{\mathrm{mp}}\right.$ & $0.54 \mathrm{~A}$ & $0.53 \mathrm{~A}$ & -1.85 \\
Açı Devre Gerilimi $\left(\mathrm{V}_{\mathrm{OC}}\right)$ & $22.61 \mathrm{~V}$ & $22.44 \mathrm{~V}$ & -0.75 \\
Kısa Devre Akımı $\left(\mathrm{I}_{\mathrm{SC}}\right)$ & $0.56 \mathrm{~A}$ & $0.56 \mathrm{~A}$ & 0.00 \\
\hline
\end{tabular}




\section{Tasarlanan FV Panel Emülatör Performansının İncelenmesi}

Geliştirilen emülatörün doğrulanması için Şekil 9'da verilen deney düzeneği hazırlanmıştır. Bu düzenek ile emülatörün temel elektriksel parametreleri elde edilmiş, grafiksel incelemeler yapılmış, FV panel için geliştirilen dijital ikiz kullanılarak doğrulama işlemi gerçekleştirilmiştir. $25{ }^{\circ} \mathrm{C}$ referans sıcaklık değeri için gerçekleştirilen deneysel çalışma neticesinde FV panel emülatörü için elde edilen temel elektriksel veriler Çizelge 3'te, FV panel emülatörü ile dijital ikizin temel elektriksel verilerinin karşılaştırıldığı grafik Şekil 10'da verilmiştir. Elde edilen sonuçlar, literatürde FV panel emülatörleri için elde edilen sonuçlar ile (Can, 2013; Gürkan ve ark., 2020; İşen ve Koçhan, 2020) uyumludur.

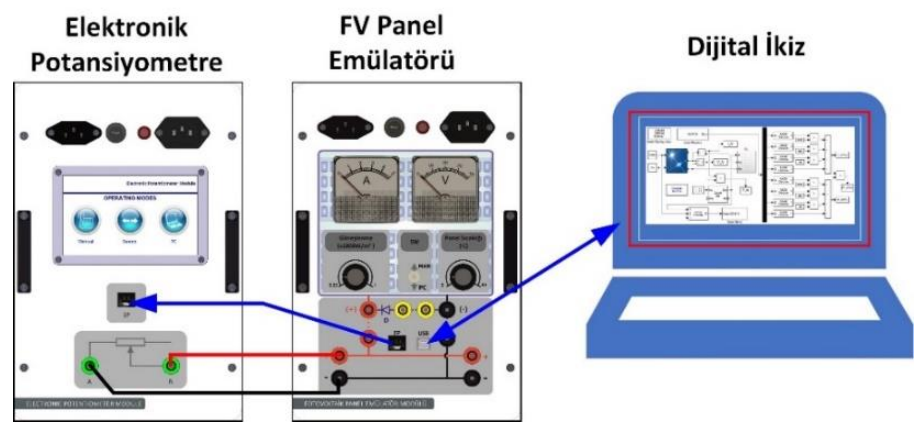

Şekil 9. FV panel emülatörünün doğrulanması için hazırlanan deney düzeneği

Çizelge 3. FV panel emülatörü için elde edilen temel elektriksel veriler

\begin{tabular}{lccccc}
\hline Parametre & $\begin{array}{c}\text { Referans FV } \\
\text { Panel Değeri }\end{array}$ & $\begin{array}{c}\text { Dijital İkiz } \\
\text { Değeri }\end{array}$ & $\begin{array}{c}\text { Emülatör } \\
\text { Değeri }\end{array}$ & $\begin{array}{c}\text { Fark-1 } \\
(\boldsymbol{\%})\end{array}$ & $\begin{array}{c}\text { Fark-2 } \\
(\boldsymbol{\%})\end{array}$ \\
\hline Maksimum Güç $\left(\mathrm{P}_{\mathrm{max}}\right)$ & $10.03 \mathrm{~W}$ & $9.98 \mathrm{~W}$ & $10.01 \mathrm{~W}$ & $-0,20$ & +0.30 \\
Maksimum Güç Gerilimi $\left(\mathrm{V}_{\mathrm{mp}}\right)$ & $18.70 \mathrm{~V}$ & $18.56 \mathrm{~V}$ & $18.43 \mathrm{~V}$ & $-1,47$ & -0.70 \\
Maksimum Güç Akımı $\left(\mathrm{I}_{\mathrm{mp}}\right)$ & $0.54 \mathrm{~A}$ & $0.53 \mathrm{~A}$ & $0.54 \mathrm{~A}$ & 0,00 & +1.85 \\
Açı Devre Gerilimi (V) & $22.61 \mathrm{~V}$ & $22.44 \mathrm{~V}$ & $22.27 \mathrm{~V}$ & $-1,53$ & -0.76 \\
Kisa Devre Akımı (ISC) & $0.56 \mathrm{~A}$ & $0.56 \mathrm{~A}$ & $0.57 \mathrm{~A}$ & 1.75 & 1.79 \\
\hline
\end{tabular}

Fark-1=Referans FV panel ile emülatör karşılaştırmasından elde edilen \% fark, Fark-2=Dijital ikiz ile emülatör karşılaştırmasından elde edilen \% fark.

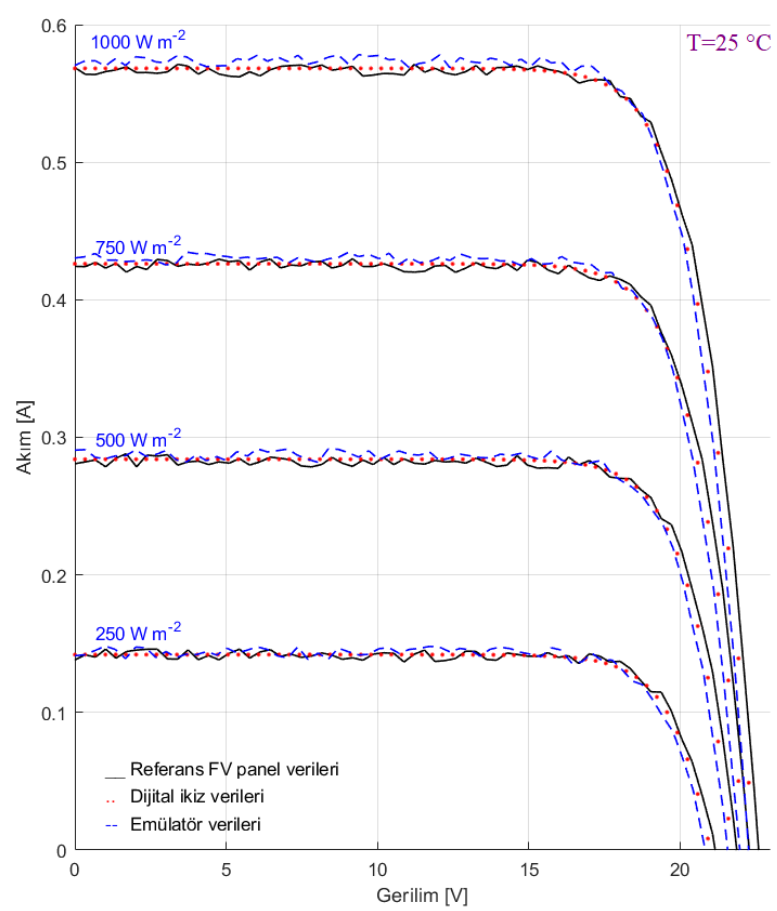

(a)

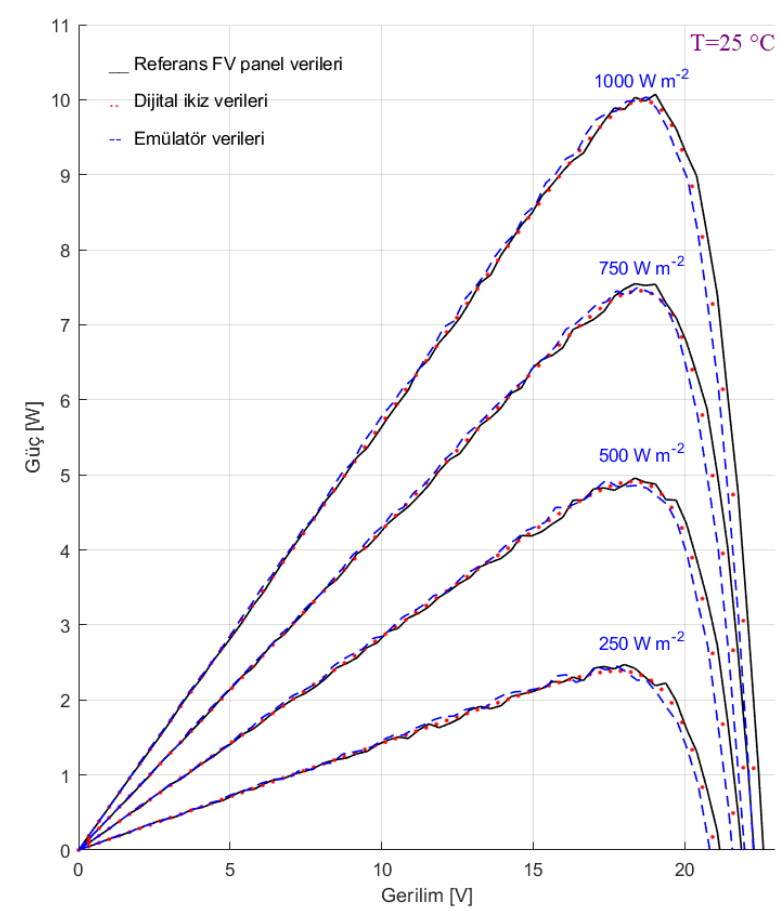

(b)

Şekil 10. FV panel emülatörü için elde edilen grafikler (a) I-V grafiği (b) P-V grafiği 
Geliştirilen FV panel emülatörünün farklı sıcaklıklardaki davranışlarını incelemek maksadıyla, Şekil 9'da verilen deney düzeneği kullanılarak bir deneysel çalışma gerçekleştirilmiştir. $1000 \mathrm{~W} \mathrm{~m}^{-2}$ güneşlenme altında, $0{ }^{\circ} \mathrm{C}, 25{ }^{\circ} \mathrm{C}, 50{ }^{\circ} \mathrm{C}$ ve $75^{\circ} \mathrm{C}$ sıcaklıkları için elde edilen sonuçlar Şekil 11 'de verilmiştir.

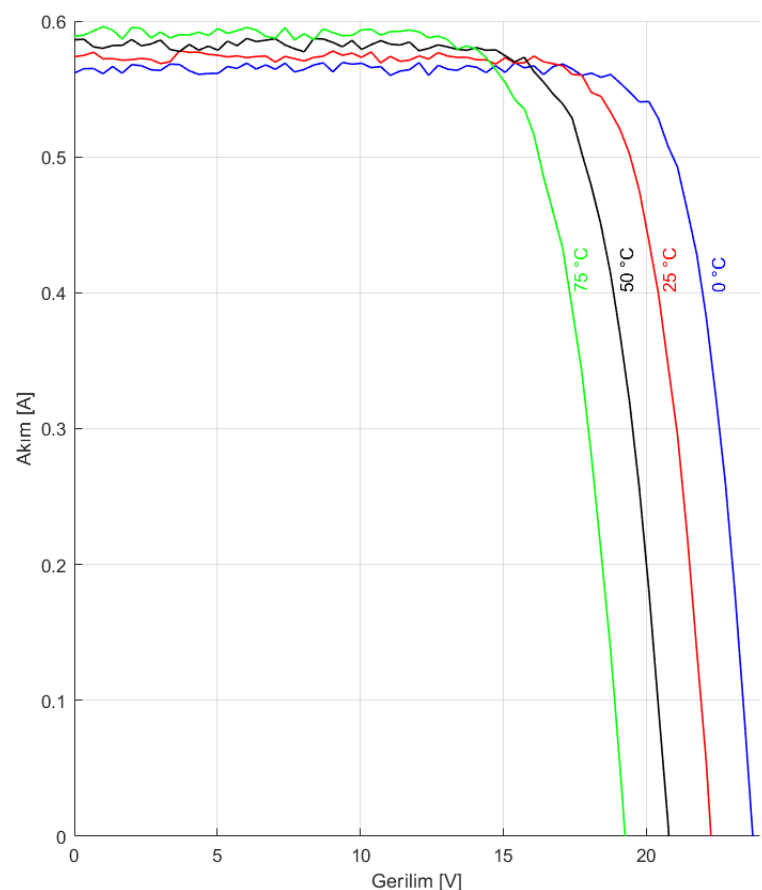

(a)

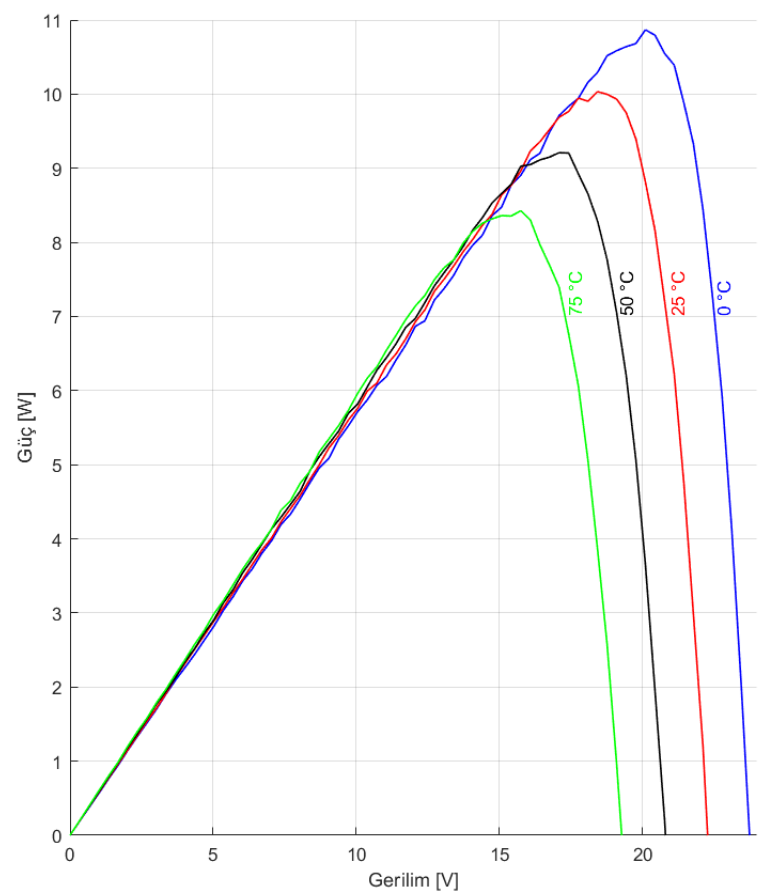

(b)

Şekil 11. FV panel emülatörü için farklı sıcaklıklar altında elde edilen grafikler (a) I-V grafiği (b) P-V grafiği

\section{SONUÇ}

Bu çalışmada, TERA Solar TRP-010B FV panel referans alınarak bir FV panel emülatörü tasarlanmıştır. Tasarlanan donanımın test edilmesi ve doğrulanması için Matlab Simulink ortamında FV panele ait bir dijital ikiz oluşturulmuştur. Referans panel için deneysel çalışmalarla elde edilen temel elektriksel verilerin ve grafik sonuçların, panele ait veri sayfasındaki değerlerle uyumlu olduğu görülmüştür. FV panel için oluşturulan dijital ikiz ile gerçekleştirilen deneysel çalışmalar neticesinde elde edilen temel elektriksel verilerin ve grafiksel sonuçların da referans panel verileri ile uyumlu olduğu görülmüştür. Dijital ikiz için elde edilen temel elektriksel verilerde en yüksek hata, \%-1.85 ile maksimum güç akımı parametresinde meydana gelmiştir. Geliştirilen FV panel emülatörü ile gerçekleştirilen deneysel çalışmalarda, FV panel emülatörü temel elektriksel verileri ve grafik sonuçlarının dijital ikiz için elde edilen sonuçlarla uyumlu olduğu görülmüştür. FV panel emülatörü için elde edilen temel elektriksel verilerde en yüksek hata \%1.85 ile kısa devre akımı parametresinde meydana gelmiştir. Tüm sonuçlar birlikte değerlendirildiğinde FV panel, FV panel dijital ikizi ve FV panel emülatörüne ait sonuçların yüksek oranda uyumluluk gösterdiği gözlemlenmiştir. Bu bilgiden hareketle; tasarlanarak prototip imalatı gerçekleştirilen FV panel emülatörünün, referans panel ile gerçekleştirilecek deneysel çalışmalarda kullanılabileceği kıymetlendirilmektedir.

Şekil 3 ve Şekil 9'da verilen deney düzenekleri karşılaştırıldığında; FV panellerin gerçek şartlarda test edilmesi veya deneysel çalışmalar gerçekleştirilmesi esnasında fazla miktarda donanıma ihtiyaç duyulduğu, FV panel emülatörü kullanımı ile donanım ihtiyacının azaldığı ve zamandan tasarruf sağlandığı sonucuna ulaşılmaktadır. Referans panel ile gerçekleştirilen çalışmalarda farklı sıcaklıklar için deneysel çalışma gerçekleştirilmemiştir. Ancak dijital ikiz ve FV emülatör ile farklı sıcaklıklar için 
gerçekleştirilen çalışmalarda elde edilen verilerin, referans panel katalog verileri ile uyumlu olduğu görülmüştür. Böylelikle, dijital ikiz kavramı için geçerli olan fiziki hedef hakkında yeni ve güvenilir verilerin elde edilebilmesi teorisini destekleyen bir sonuç elde edilmiştir.

\section{Çıkar Çatışması}

Makale yazarları aralarında herhangi bir çıkar çatışması olmadığını beyan ederler.

\section{Yazar Katkısı}

Yazarlar makaleye eşit oranda katkı sağlamış olduklarını beyan ederler.

\section{KAYNAKLAR}

Anonim, 2018, TRP Serisi Polikristal Fotovoltaik Paneller, http://www.tera-solar.com/upload/ dosyalar/TERA_SOLAR_250W_300W_Fotovoltaik_Panel.pdf (Erişim Tarihi: 01.10.2021).

Anonim, 2019, Renewable Energy Trainer, https://www.heliocentrisacademia.com/product/renewable_ energy_trainer (Erişim Tarihi: 01.10.2021).

Anonim, 2020, Statistical Review of World Energy, https://www.bp.com/content/dam/bp/business-sites/ en/global/corporate/pdfs/energy-economics/statistical-review/bp-stats-review-2020-fullreport.pdf (Erişim Tarihi: 01.10.2021).

Anonim, 2021, EPH 3 Professional Photovoltaics Trainer (PV), https://www.lucasnuelle.us/2768/apg/13261/ EPH-3-Professional-Photovoltaics-Trainer-PV-.htm (Erişim Tarihi: 01.10.2021).

Alqahtani A, Alsaffar M, El-Sayed M, Behbehani H, 2018. A photovoltaic system experiment in a laboratory environment. The International Journal of Electrical Engineering \& Education, 55(1):31-43.

Aydın İ, 2014. Balıkesir'de Rüzgâr Enerjisi. Doğu Coğrafya Dergisi, 18:29-50.

Bartie NJ, Cobos-Becerra YL, Fröhling M, Schlatmann R, Reuter MA, 2021. The resources, exergetic and environmental footprint of the silicon photovoltaic circular economy: Assessment and opportunities. Resources, Conservation and Recycling, 169:105516.

Bayramoğlu T, 2018. Yenilenebilir Enerji Potansiyeli ve Etkileri: Bayburt Örneği. İşletme Ekonomi ve Yönetim Araştırmaları Dergisi, 1(1):1-16.

Boschert S, Rosen R, 2016. Digital Twin---The Simulation Aspect. In: Hehenberger P, Bradley D, eds. Mechatronic Futures: Challenges and Solutions for Mechatronic Systems and their Designers, 5974, Cham: Springer International Publishing;

Can H, 2013. Model of a photovoltaic panel emulator in MATLAB-Simulink. Turkish Journal of Electrical Engineering and Computer Science, 21:300-308.

Fuller A, Fan Z, Day C, Barlow C, 2020. Digital Twin: Enabling Technologies, Challenges and Open Research. IEEE Access, 8:108952-108971.

Gençer Ç, Akkaya S, Gürkan S, 2009. Wind Energy Potential In Turkey And Case Study Of Three Projects. 5th International Advanced Technologies Symposium (IATS'09). 1-4, Karabük,Türkiye;

Grieves M, 2006.Product lifecycle management: driving the next generation of lean thinking NewYork: McGraw-Hill Education.

Grieves M, 2016. Origins of the Digital Twin Concept

Guarino A, Monmasson É, Spagnuolo G, 2021. SoC-based embedded real-time simulation of mismatched photovoltaic strings. Mathematics and Computers in Simulation, 184:267-281.

Gürkan S, Karapınar M, Sorgunlu H, Öztürk O, Doğan S, 2020. Development of a photovoltaic panel emulator and LabVIEW-based application platform. Computer Applications in Engineering 
Education, 28(5):1291-1310.

İşen E, Koçhan Ö, 2020. Fotovoltaik Panelin Tek Diyotlu Modellenmesi. Mühendislik Bilimleri ve Araştırmaları Dergisi, 2(1):2-10.

Kacan E, 2015. Renewable energy awareness in vocational and technical education. Renewable Energy, 76:126-134.

Kavcıoğlu Ş, 2019. Yenilenebilir Enerji ve Türkiye. Finansal Araştırmalar ve Çalışmalar Dergisi, 11(21):209-227.

Kaya K, Şenel MC, Koç E, 2018. Dünyada ve Türkıye'de Yenilenebillr Enerji Kaynaklarının Değerlendirilmesi. Technological Applied Sciences, 13:219-234.

Khaled N, Pattel B, Siddiqui A, 2020. 6 - Digital twin model creation of solar panels. In: Khaled N, Pattel B, Siddiqui A, eds. Digital Twin Development and Deployment on the Cloud. 137-162, Academic Press;

Kumaş E, Erol S, 2021. Endüstri 4.0'da Anahtar Teknoloji Olarak Dijital İkizler. Politeknik Dergisi, Erken Görünüm.

Rosen R, von Wichert G, Lo G, Bettenhausen KD, 2015. About The Importance of Autonomy and Digital Twins for the Future of Manufacturing. IFAC-PapersOnLine, 48(3):567-572.

Senthilnathan K, Annapoorani I, 2019. Cyber Twin Approach for Smart Grids. IEEE Smart Grid

Shangguan D, Chen L, Ding J, 2020. A Digital Twin-Based Approach for the Fault Diagnosis and Health Monitoring of a Complex Satellite System. Symmetry, 12(8)

Tagare DM, 2011.Electric Power Generation Wiley.

Tao F, Cheng J, Qi Q, 2017. Digital twin-driven product design, manufacturing and service with big data. The International Journal of Advanced Manufacturing Technology, 94(2018):3563-3576.

Yılmaz EA, Öziç HC, 2018. Türkiye'nin Yenilenebilir Enerji Potansiyeli ve Gelecek Hedefleri. Ordu Üniversitesi Sosyal Bilimler Araştırmaları Dergisi, 8(3):525-535. 